\title{
Medical Professionals and Smartphone Applications
}

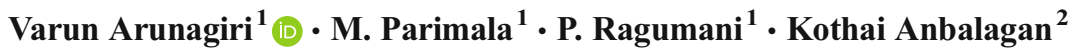

Received: 16 October 2016 / Accepted: 13 March 2017 / Published online: 22 March 2017

(C) Association of Surgeons of India 2017

\begin{abstract}
Ever since the advent of Smartphones, Smartphone applications (SAs) are revolutionizing the contemporary medicine. Smartphone application which was created in view of swift communications among the general public has now intruded the medical fraternity. But the ethics for using these applications to transfer patients' medical records through SA is bewildering among the medical professionals (MPs).
\end{abstract}

Keywords Medical professionals · Smartphone applications · WhatsApp · Ethics $\cdot$ Consent

A questionnaire-based electronic survey was done using SurveyMonkey ${ }^{\mathrm{TM}}$ among the medical professionals (MPs). Two hundred seven medical professionals of various hierarchy participated. Many of the participants were Indian MPs $(n=176)$ (Fig. 1). Of the 207 MPs, few participants skipped critical questions, pertaining to medical ethics $(n=10)$ and consent from the patients to transfer the images and health records $(n=6)$. To a surprise, many doctors did not get consent to share the

Varun Arunagiri

surgeonvarun@yahoo.com

1 Institute of General Surgery, Madras Medical College, Chennai, TN, India

2 Chennai Corporation, Chennai, India medical records through Smartphone application (SA) ( $n=119 ; 59.20 \%)$. Though MPs share the patient's medical records with their colleagues $(n=117$; $56.80 \%$ ), they preferred to do it in a closed group and also with data encryption $(n=73 ; 35.27 \%)$. Of the 89 participants who did not share patient details in SAs, thought that they would do so if the SAs had end to end data encryption $(n=77 ; 86.52 \%)$. There was a slight increase in getting consent from the patient to share details in SAs among the MPs from others countries (Fig. 2) compared to Indian MPs [1, 2].

Even though MPs started using SA in their routine medical and surgical practice, ranging from simple text message broadcasting to opinion seeking and giving, many fail to adhere to medical ethics and consent taking. Before MPs face major medico-legal issues, policies regarding sharing of medical records on SAs have to be strengthened. The Health Insurance Portability and Accountability Act, General Medical Council had given policies regarding sharing of patients' details in electronic forms [3]. But if it is for SAs, this becomes perplexing. 
Fig. 1 Bar chart showing percentage $(\%)$ of Indian MPs who share (Yes) and do not share (No) the patients' details through SAs

Fig. 2 Bar chart showing comparison between Indian MPs and others MPs in getting consent form to share the patients' details in SAs

Acknowledgement None.

\section{Compliance with Ethical Standards}

Conflict of Interest The authors declare that they have no conflict of interest.

Sources of Support None.
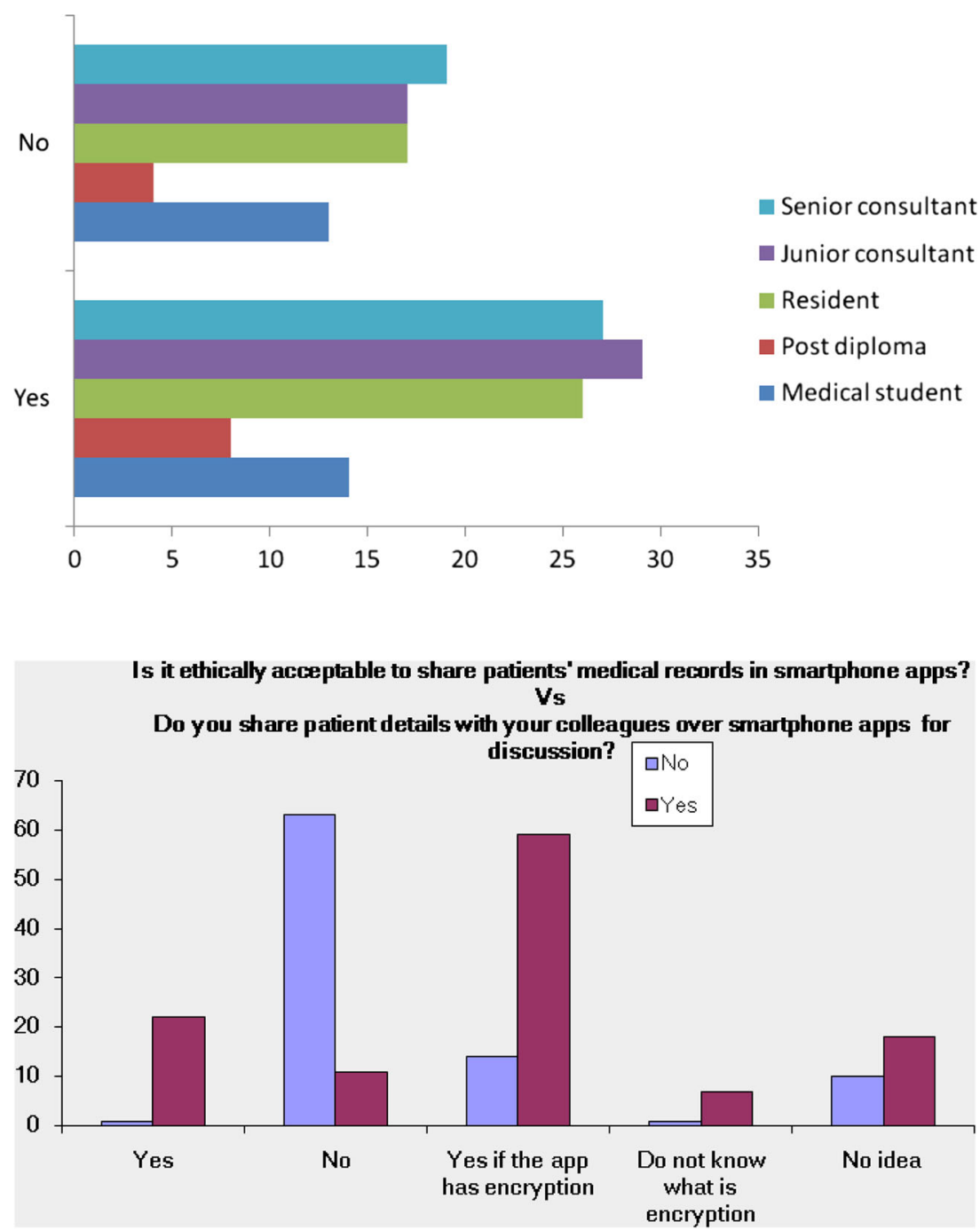

\section{References}

1. Cleland H, Ross R, Kirk M, Hunter-Smith DJ (2013) Clinical photography: surgeons need to get smart. ANZ J of Surg 83:6001. doi: 10.1111/ans. 12248

2. Kunde L, McMeniman E, Parker M (2013) Clinical photography in dermatology: ethical and medico-legal considerations in the age of digital and smartphone technology. Australas J Dermatol 54(3):192-197

3. Harting MT, DeWees JM, Vela KM, Khirallah RT (2015) Medical photography: current technology, evolving issues and legal perspectives. Int J Clin Pract 69(4):401-409 